\title{
Clareamento de Hiperpigmentação pós-Inflamatória axilar por intermédio do Carvão Ativado associado ao Mel e a Própolis
}

\author{
Patricia Angelica Chaves Costa ${ }^{1}$; Marcelo José Costa Lima Espinheira ${ }^{2}$
}

\begin{abstract}
Resumo: Dentre as principais causas da hiperpigmentação pós-inflamatória axilar estão a gestação, bactérias por vestígio de certos desodorantes ou atrito por roupas apertadas. O Carvão Ativado apresenta propriedades antioxidante, anti-inflamatória, absorvente, bactericida e clareadoras, e a associação deste componente com o mel e a própolis proporciona além da principal função para clareamento, o aumento da hidratação da pele através da indução de vitaminas e minerais presentes no mel e própolis. Atualmente existem vários tratamentos disponíveis para o clareamento da hiperpigmentação pós-inflamatória axilar, entretanto nenhum método dispõe da utilização da associação dessas substâncias para estes fins. Nesta perspectiva, este estudo tem como objetivo geral: avaliar o uso do carvão ativado associado ao mel e a própolis como clareador para hiperpigmentação pós-inflamatória na axila. Trata-se de uma pesquisa classificada como estudo de caso do tipo exploratório, a ser realizada junto a nove voluntárias que serão atendidas em um Centro Estético de uma instituição privada no interior do estado da Bahia. O instrumento de pesquisa será constituído por anamnese e exame clínico, sendo realizadas fotografias antes, durante e após o tratamento. Os dados serão analisados de forma descritiva e apresentados na forma de fotografias.
\end{abstract}

Palavras- chave: Hiperpigmentação. Carvão Ativado. Mel. Própolis.

\section{Whitening of Post-Inflammatory Hyperpigmentation Armpit Through by Activated Charcoal Associated with Honey and Propolis}

\begin{abstract}
Among the main causes of post-inflammatory axillary hyperpigmentation are gestation, bacteria from the presence of certain deodorants, or friction from tight clothing. Activated charcoal has antioxidant, anti-inflammatory, absorbent, bactericidal and whitening properties, and the association of this component with honey and propolis provides besides the main function for whitening, the increase of hydration of the skin through the induction of vitamins and minerals present in honey and propolis. Currently there are several treatments available for the clarification of axillary post-inflammatory hyperpigmentation, however no method has the use of the association of these substances for these purposes. In this perspective, this study aims to evaluate the use of activated charcoal associated with honey and propolis as a bleaching agent for postinflammatory hyperpigmentation in the axilla. It is a research classified as an exploratory case study, to be carried out with nine volunteers who will be assisted in an Aesthetic Center of a private institution in the interior of the state of Bahia. The research instrument will consist of anamnesis and clinical examination, and photographs will be taken before, during and after treatment. The data will be analyzed descriptively and presented in the form of photographs.
\end{abstract}

Keywords: Hyperpigmentation. Activated Carbon. Honey. Propolis.

\footnotetext{
${ }^{1}$ Graduanda do Curso de Estética e Cosmética da Faculdade Independente do Nordeste/FAINOR.

Contato: ticachavesc@gmail.com;

${ }^{2}$ Biólogo graduado pela Universidade Católica do Salvador/UCSAL, Pós-graduado em Metodologia e Gestão do Ensino Superior pela Faculdade Independente do Nordeste/FAINOR e Mestre em Religião/Educação na linha de pesquisa sobre Ética/Gestão pela Faculdades EST. Atualmente leciono na FAINOR, FTC e UNINASSAU. Possui experiência em Botânica, atuando na área de Florística, Fitossociologia e PRAD. Também, atuou na área da Ecologia, Ecologia Nutricional de Insetos, Herpetologia, Biotério e Resgate de Fauna.Contato: marcelo.espinheira@yahoo.com.br.
} 


\section{Introdução}

No Brasil uma das razões mais frequentes para consultas dermatológicas, constituindo cerca de $8,5 \%$ das mesmas, são as alterações na cor da pele, que causam maior impacto por serem influenciadas pelo clima quente em todas as estações do ano (CESTARI, 2014).

A pele é constituída por Epiderme, Derme e Hipoderme. A melanina é uma proteína, sintetizada pelos melanócitos fixados na derme, e que, quando estimulados, seja por fatores intrínsecos ou extrínsecos, podem desenvolver discromias. Uma delas é a hipercromia, que constitui no escurecimento de áreas que assumem um aspecto mais escuro em relação à tonalidade normal da pele, a disfunção à ser tratada no presente estudo (MIOT et al. 2009; NICOLETTI et al. 2002; GONCHOROSKI; CORRÊA, 2005).

As hiperpigmentações decorrentes de processos inflamatórios, sendo um dos principais fatores, são o resultado fisiopatológico de traumas ou lesões cutâneas, incluindo ações bacterianas, fúngicas ou virais, resíduos de cosméticos, e procedimentos estéticos, como a depilação, e fricção por uso de roupas apertadas. Esta hiperpigmentação também é estimulada pelas irritações provocadas por meio da forma de secagem da região e dos movimentos de alongamento e contração realizados pelos membros superiores e inferiores. (GONCHOROSKI; CORRÊA, 2005; JAMES et al. 2006; ALCHORNE; ABREU, 2008; RIBEIRO,2010).

Diversos estudos, demonstram que o carvão ativado, o mel e a própolis possuem ação antioxidante e anti-inflamatória sendo que o carvão ainda apresenta funções absorvente, bactericida e clareadora (PAIVA; MENEZES, 2003; GUILARDUCI et al, 2006; RAMOS et al, 2009) e o mel e a própolis com ação antimicrobiana e antifúngica, por possuírem flavonoides entre outras substâncias na sua composição (LONGHINI et al., 2007; VENTURINI; SARCINELLI; SILVA, 2007; DIAS et al., 2015; OLIVEIRA et al., 2015; PEREIRA et al., 2015).

O presente estudo tem como proposta avaliar a eficácia da utilização do carvão ativado associado ao mel e a própolis como clareador, para tratar a hiperpigmentação das axilas decorrente de processos inflamatórios. 


\section{Referencial Teórico}

\section{A Pele}

A pele é o maior órgão do corpo humano sendo cerca de 5\% do seu peso total, agindo como um envoltório de proteção ao meio externo controlando a perda de fluidos corporais, evitando a entrada de substâncias estranhas e nocivas no organismo, mantendo a temperatura do corpo constante, atuando assim como um revestimento protetor e uma barreira impermeável a muitas substâncias (GONCHOROSKI; CORRÊA, 2005); (ALEXANDER; EGGERT; WIEST, 2018)

A pele é dividida em três camadas com funções distintas. A mais externa e principal barreira de defesa é a epiderme; a intermediária e vascularizada é conhecida como derme; e a mais profunda, constituída de tecido gorduroso, a hipoderme (BORGES,2010).

A epiderme é a camada superficial da pele, que tem a função de proteção contra agentes externos, é constituída por um epitélio escamoso estratificado, composto por cinco tipos de células histologicamente diferentes, organizadas em cinco camadas, da superficial à mais profunda: estrato córneo ( camada corneificada); estrato lúcido (camada clara); estrato granular (camada granulosa); estrato espinhoso (camada espinhosa); e, por fim, o estrato basal, que corresponde à camada regenerativa (BORGES, 2010).

A derme é a faixa mais densa da pele, composta por fibras colágenas, elásticas e reticulínicas, que a torna resistente e elástica. Suas fibras elásticas apoiam a epiderme e fixam a hipoderme, e também estão presente anexos cutâneos dos tipos córneos (pêlos e unhas) e glandulares (glândulas sebáceas e sudoríparas), nervos e terminações nervosas. Representa a segunda linha de proteção contra traumatismos e é responsável pela vascularização da epiderme, auxiliando nas funções de termorregulação e percepção do ambiente (BORGES,2010).

Já a hipoderme, a camada mais profunda da pele, é basicamente formada por tecido adiposo e divisões fibrosas por onde passam vasos e nervos cutâneos de maior calibre. Desempenha funções de reservatório nutritivo, conservação da temperatura corporal e proteção mecânica do organismo contra pressões e traumatismos externos (GONCHOROSKI; CORRÊA, 2005). 


\section{Escurecimento da pele}

As alterações na coloração da pele são as mais comuns e as que geram maior preocupação para as mulheres. A cor da pele é determinada por diversos fatores, sendo o principal deles a presença da melanina, sintetizada por melanócitos (MIOT et al., 2009). A estimulação dos melanócitos, seja por fatores intrínsecos ou extrínsecos, pode aumentar a produção de melanina, desenvolvendo assim as hipercromias ou hiperpigmentações, que são concomitantemente o escurecimento de áreas que assumem um aspecto mais escuro em relação à tonalidade normal da pele (NICOLETTI et al. 2002; GONCHOROSKI; CORRÊA, 2005).

\section{As desordens da coloração da pele}

A discromia é um termo empregado para variações de pigmentação do tecido cutâneo, referindo -se à quantidade de melanina, ou a outros pigmentos endógenos e exógenos. As discromias podem ser classificadas como acromias (ausência de melanina), hipocromias (diminuição da melanina), hipercromias (aumento da melanina) leucomelanodermias (associação de hipocromias e hipercromias). (AZULAY,2011)

As hipocromias (vitiligo) e as acromias (albinismo), assim como a hiperpigmentação podem ser hereditárias, congênitas ou adquiridas, dentre as principais hipercromias estão as manchas mongólica, efélides (sardas), lentigo (lentingens), fitofotodermatite, melasma e o objetivo deste estudo a hiperpigmentação pósinflamatória (AZULAY,2011; HENDEL, 2014)

Os principais fatores que estimulam as hiperpigmentações, são: exposição solar, gestação, alterações hormonais, alergias, envelhecimento e inflamações (GONCHOROSKI; CORRÊA, 2005). Quando a hiperpigmentação é decorrente de processos inflamatórios, recebe o nome de hiperpigmentação pós-inflamatória, que é o resultado fisiopatológico adquirido através de traumas ou lesões cutâneas. (ALCHORNE; ABREU, 2008).

Várias são as etiologias, incluindo infecções bacterianas, fúngicas ou virais, doenças inflamatórias, tais como acne, líquen plano, psoríase e pseudofoliculite; reações de hipersensibilidade induzidas por drogas ou por dermatite atópica, causada por agentes físicos ou químicos, incluindo procedimentos estéticos (ALCHORNE; ABREU, 2008). 
Sendo atribuída a hiperpigmentação pós-inflamatória, esta decorre do atrito da roupa sobre a pele, a forma de secagem da região e dos movimentos de alongamento e contração realizados pelos membros superiores e inferiores (JAMES et al., 2006). A forma de depilação e o uso de determinados produtos também podem provocar irritações na região e posteriormente, manchá-la (RIBEIRO, 2010).

A axila é uma área composta por folículos, glândulas sudoríparas, gânglios linfáticos, reservas de gordura e ainda abriga a passagem de vasos e artérias. A transpiração que ocorre nesta área do corpo, em conjunto com a ação de microorganismos residentes nos pelos, causa a formação de odores, pois é composta na sua maioria pelo suor, e também por feromônios $\mathrm{O}$ suor em si não possui odor, porém, é causado por ação bacteriana. A hiperpigmentação axilar pode ser causada por estes fatores e também pode ocorrer com o uso de determinados desodorantes ou até mesmo com a depilação (SOUZA; JUNIOR, 2013).

A homogeneidade na coloração da pele é uma preocupação constante, pois as manchas produzem um aspecto indesejado, impactando negativamente na autoestima dos pacientes (RIBEIRO, 2010). Portanto, justifica-se a importância de buscar alternativas para o tratamento da hiperpigmentação nas axilas, promovendo a uniformização da tonalidade da região e elevando a estima dos pacientes.

De acordo com Ribeiro (2010), o clareamento das hiperpigmentações depende do tipo e da intensidade que estas apresentam, mas é basicamente realizado por meio de substâncias clareadoras.

\section{Clareadores}

O ácido glicólico é um agente despigmentante derivado da cana-de-açúcar, facilmente encontrado em formulações cosméticas, em baixas concentrações tem efeito de hidratação na pele, e em concentrações mais altas é convertido em esfoliante por afinar o estrato córneo diminuindo a ligação entre os corneócitos. É indicado para o tratamento de hipercromias, principalmente quando associado a outros despigmentantes (GONCHOROSKI; CORRÊA, 2005; RIBEIRO, 2010).

O Ácido Kójico é adquirido através da fermentação do arroz, sendo capaz de inibir a tirosinase, proteína responsável pela produção de melanina. Seu uso é vantajoso, 
pois além de não ser citotóxico e nem irritativo, não é fotossensível (GONCHOROSKI; CORRÊA, 2005).

O Ácido Retinóico, vitamina A ácida ou ainda conhecido com tretinoína, é uma substância lipossolúvel que necessita da presença de uma proteína específica (CRABP) para ser transportado, cujos níveis são maiores na epiderme do que na derme, ele atua na hiperpigmentação através do efeito esfoliativo e dispersando os grânulos de melanina dentro dos queratinócitos, ou seja, diminui o tempo de contato entre os queratinócitos e os melanócitos, promovendo uma perda rápida do pigmento disperso, garantindo uma uniformidade na aplicação do agente peeling, promovendo uma reepitelização mais rápida (GONCHOROSKI; CORRÊA, 2005).

A Hidroquinona, por ser hidrossolúvel, é facilmente incorporada a formulações, mas quando estas entram em contato com o ar oxidam, necessitando adição de antioxidantes e ajuste no pH (4-6) para estabilização, além de poder causar irritações cutâneas como queimação e vermelhidão, altas concentrações e o uso contínuo podem levar a uma síndrome causada pelo acúmulo de ácido nos tecidos conjuntivos tendo efeito citotóxico sobre os melanócitos (GONCHOROSKI; CORRÊA, 2005).

O Carvão Ativado é sintetizado a partir de madeira e vegetais, sendo uma forma quase grafítica de carbono, de partículas de tamanho pequeno; apresenta diversas funções tais como clareador, deodorizador, decolorizador e filtrador, antibacteriano, antiinflamatório (PAIVA; MENEZES, 2003; GUILARDUCI et al, 2006; RAMOS et al, 2009).

\section{Tratamento}

Por todas as propriedades curativas do Carvão Ativado é que propomos neste estudo, associá-lo ao Mel e Própolis com o objetivo de além de tratar a hiperpigmentação pós-inflamatória, restaurar e nutrir o tecido axilar.

A própolis e o mel são formam uma variedade de substâncias que as abelhas coletam de plantas, com o objetivo de vedar a colmeia. Estas misturas são constituídas por cerca de $47 \%$ de resina composta por vitaminas, sais minerais, compostos fenólicos como flavonoides, ácidos graxos, álcoois aromáticos e ésteres, 30\% de ceras, 5\% de pólen, 4- 15\% de substâncias voláteis e matérias questionável e 13\% de substâncias desconhecidas. Dentre as substâncias presentes destacam- se os flavonoides, os quais são 
indicados como responsáveis pelas ações, antioxidante, anti-inflamatória, antimicrobiana e, em especial pela antifúngica (LONGHINI et al., 2007; VENTURINI; SARCINELLI; SILVA, 2007; DIAS et al., 2015;

OLIVEIRA et al., 2015; PEREIRA et al., 2015). Assim sendo, a própolis e o mel serão utilizados na formulação como diluidor do carvão ativado e veículo para a aplicação da mesma na região a ser tratada.

\section{Metodologia}

O presente estudo trata-se de uma pesquisa exploratória, com finalidade de promover a familiaridade com o problema, buscando torná-lo mais explícito ou construir hipóteses (GIL, 2010). Por ser uma pesquisa muito específica, esta atribui uma forma de estudo de caso. Quanto à abordagem é do tipo qualitativa em que possibilita o aprofundamento da investigação das perguntas que estão relacionadas ao fenômeno em estudo e suas afinidades, mediante a grande valorização do contato direto com o caso estudado (GIL, 1999).

A pesquisa foi realizada em um Centro Estético de uma Instituição privada, localizada no interior do estado da Bahia. A amostra deste estudo foi representada por nove voluntárias do sexo feminino, que possuiam hiperpigmentação pós- inflamatória nas axilas causada por fricção (atrito), e/ou bactérias por resíduos de cosméticos na região, com faixa etária acima de 20 anos. Além de estar de acordo a usar o protocolo sugerido assinando os termos de Consentimento Livre Esclarecido (ANEXO A) e Termo de autorização de uso de imagem e/ou depoimentos (Anexo B).

As participantes foram submetidas inicialmente a uma ficha anamnese e exame clínico, sendo realizadas fotografias antes, durante e após o tratamento. Este foi realizado durante um mês, associando o uso home de um sabonete de composto por argila preta ao procedimento em cabine. As sessões em cabine foram realizadas no Centro Estético de uma instituição privada, localizada no interior do estado da Bahia, e aconteceram uma vez na semana, utilizando o mesmo sabonete do home care para higienização e esfoliação das axilas antes da aplicação da mistura, de acordo sua necessidade do uso. Os dados foram analisados de forma descritiva e apresentados na forma de fotografias. 
O projeto foi submetido ao Comitê de Ética em Pesquisa da Faculdade Independente do Nordeste onde os dados somente puderam ser coletados após a autorização do referido comitê. Passado essa fase, foi dado início ao contato com as entrevistadas, com a entrega do termo de consentimento livre e esclarecido, e aplicação do instrumento conforme resolução 466/12 do CEP/FAINOR.

\section{Resultados e Discussão}

Todas as participantes se encaixaram nos critérios de inclusão do estudo; aceitaram o uso único deste protocolo pelo período necessário de aplicações; aderiram ao tratamento conforme o protocolo proposto, concordaram em assinar o Termo de Consentimento Livre e Esclarecido e a autorização de uso de suas imagens pelos pesquisadores; não apresentaram sensibilidade ou irritação no teste prévio ao produto; e também não apresentaram qualquer impedimento a sua participação como voluntária deste estudo..

Foram selecionadas 9 voluntárias do sexo feminino, com idades entre 16 e 52 anos, de idade, dessas três com fototipo II, três com fototipo III e três com fototipo IV de acordo classificação de Fitzpatrick. Com início dos atendimentos entre os meses de abril e maio do ano de 2018. Foi realizada a aplicação da mistura duas vezes por semana, sendo necessárias até quatro vezes de aplicação para comprovar sua eficácia no clareamento pós-inflamatório axilar por intermédio do Carvão Ativado associado ao Mel e a Própolis.

Considerando as respostas obtidas com o preenchimento das fichas anamnese, $100 \%$ das voluntárias não relataram antecedentes alérgicos ou doença crônica, assim como nenhum tipo de tratamento médico para as manchas axilares já realizado ou em andamento, não são fumantes e tampouco etilistas. Das participantes selecionadas apenas uma faz uso de anticoncepcional oral, três têm acima de um filho, e todas elas definem suas axilas como pigmentada ou muito pigmentada causando em algum momento constrangimento às mesmas.

Em cabine foi utilizada a associação do Carvão Ativado associado ao Mel e a Própolis com o objetivo de comprovar sua eficácia no clareamento da hiperpigmentação pós-inflamatória axilar, seguimos com aplicação da mistura composta por $20 \mathrm{~g}$ de Carvão Ativado, $10 \mathrm{ml}$ de mel e 5 gotas do estrato da própolis, durante vinte minutos após ser 
realizada a higienização local com sabonete composto por argila preta utilizando a gaze para aplicação e removendo com água, e removendo a mesma com água e repetindo a higienização com local com sabonete composto por argila preta utilizando a gaze para aplicação e removendo com água.

A partir do segundo atendimento as voluntárias perceberam a despigmentação em suas axilas, e a importância do uso do sabonete indicado para home care, considerando que a ação anti-inflamatória da argila potencializa os resultados, assim como regenera o tecido, sendo também um potente cicatrizante, deixando a pele mais hidratada e nutrida com o uso da associação dos componentes.

Em alguns casos foi observada a remoção de uma crosta, adquirida por resíduos de desodorantes, que provoca o escurecimento superficial do tecido através de fungos e bactérias. O Carvão Ativado apresenta propriedades antioxidante, anti-inflamatória, absorvente, bactericida e clareadoras, e a associação deste componente com o mel e a própolis proporciona além da principal função para clareamento, o aumento da hidratação da pele através da indução de vitaminas e minerais presentes no mel e própolis. (PAIVA; MENEZES, 2003; GUILARDUCI et al, 2006; RAMOS et al, 2009).

\section{Voluntária B.S.A.}

- 23 anos, sexo feminino, parda, fototipo III de acordo a classificação de Fitzpatrick. Considera sua axila pigmentada, relatando ter percebido aos 18 anos de idade, após realizar a terceira sessão apresentou resultado na eficácia da formulação.
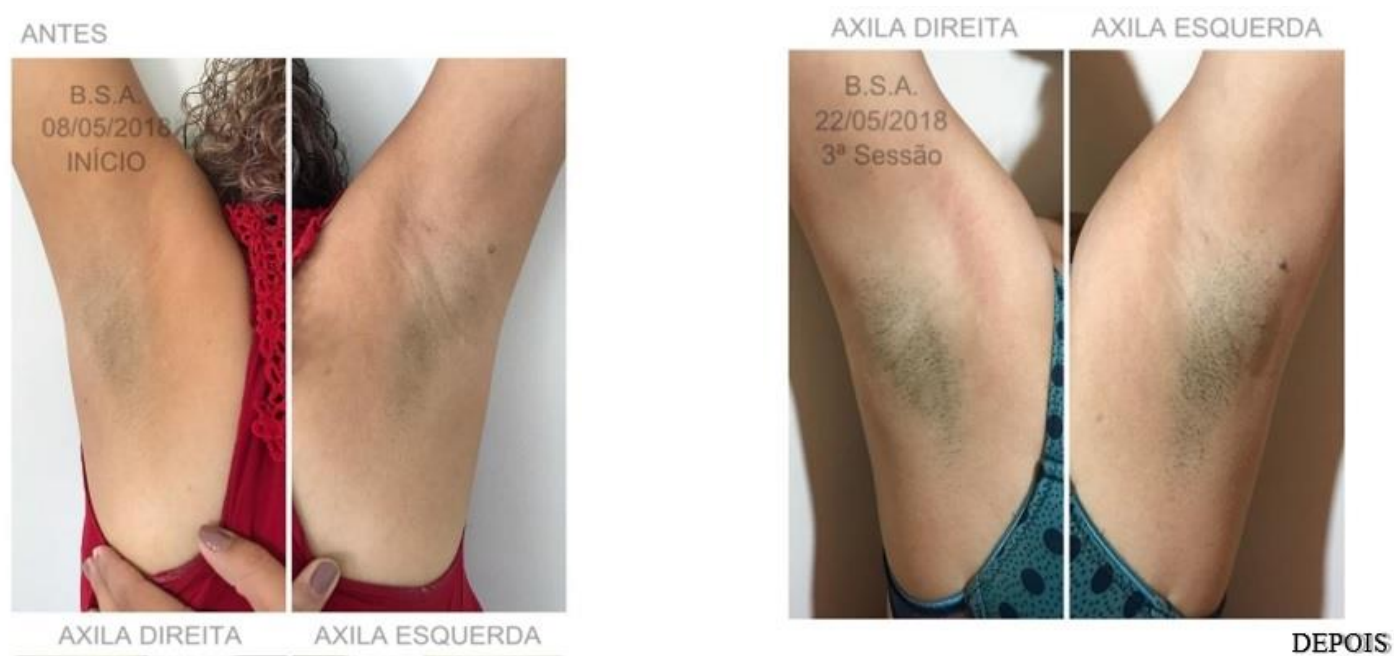


\section{Voluntária H.M.B.R.}

- 27 anos, sexo feminino, branca, fototipo II de acordo a classificação de Fitzpatrick. Considera sua axila pouco pigmentada, relatando ter percebido após os 20 anos de idade, ao realizar a segunda sessão apresentou resultado na eficácia da formulação.
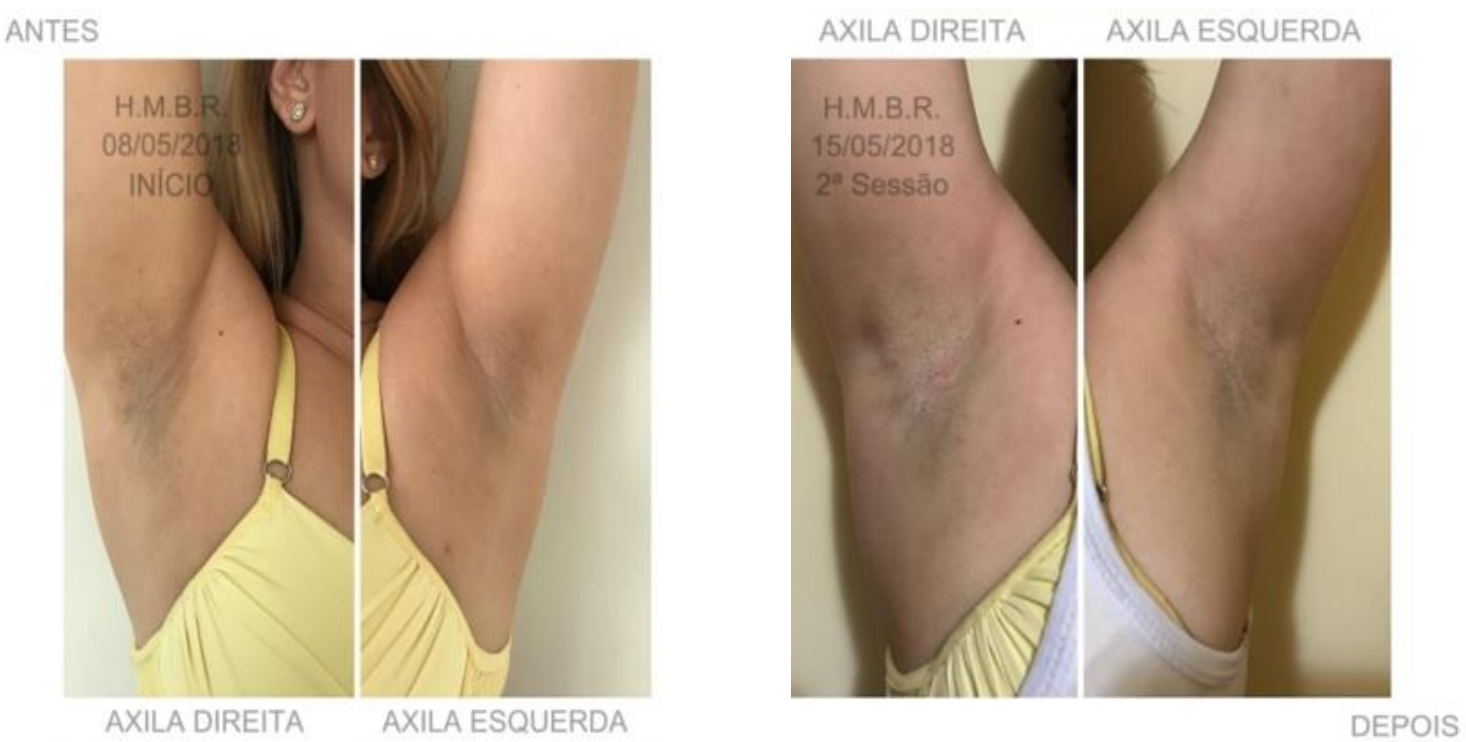

\section{Voluntária K.L.N.O.}

- 16 anos, sexo feminino, morena, fototipo III de acordo a classificação de Fitzpatrick. Considera sua axila muito pigmentada, relatando ocorrência desde a infância, após a terceira sessão apresentou resultado na eficácia da formulação.
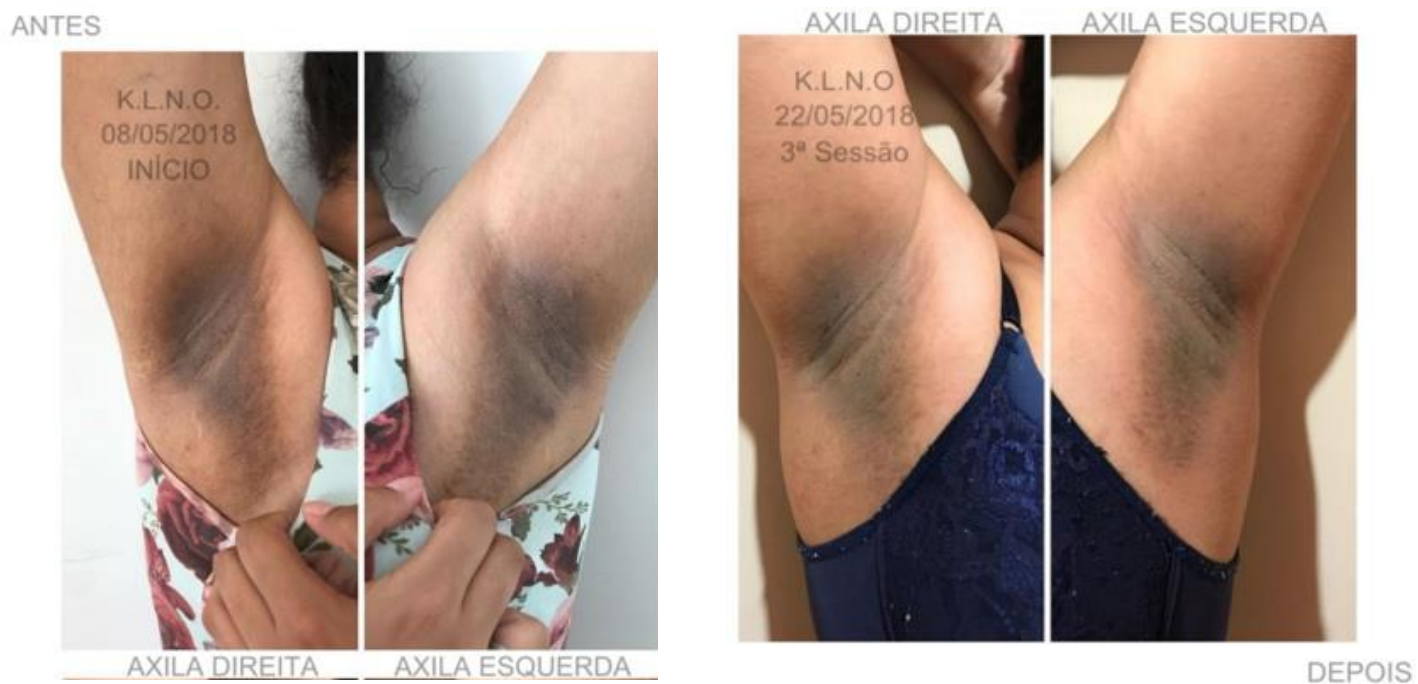


\section{Voluntária K.D.N.N.}

- 35 anos, sexo feminino, morena, fototipo IV de acordo a classificação de Fitzpatrick. Considera sua axila pigmentada, relatando ocorrência desde os 16 anos, após a terceira sessão apresentou resultado na eficácia da formulação.
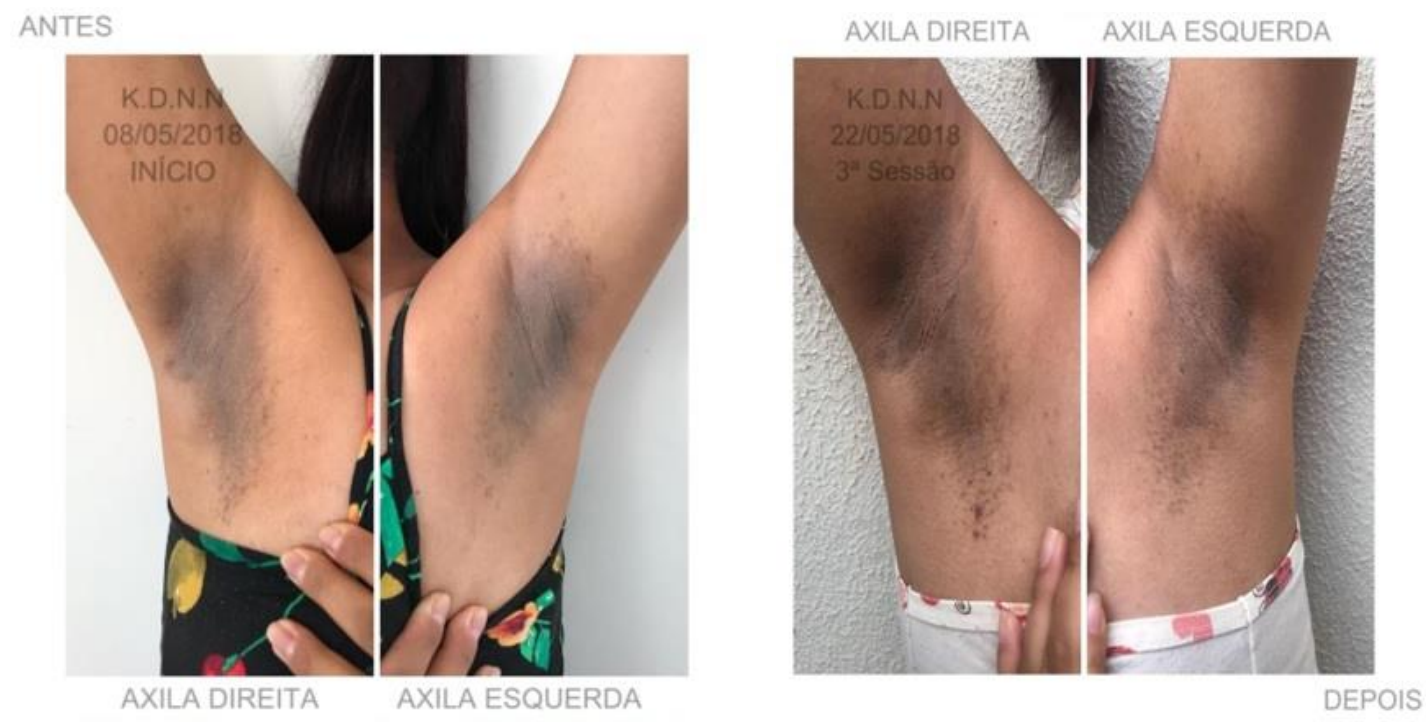

\section{Voluntária L.S.S.}

- 22 anos, sexo feminino, morena, fototipo IV de acordo a classificação de Fitzpatrick. Considera sua axila muito pigmentada, relatando ocorrência desde a infância, após a quarta sessão apresentou resultado na eficácia da formulação.
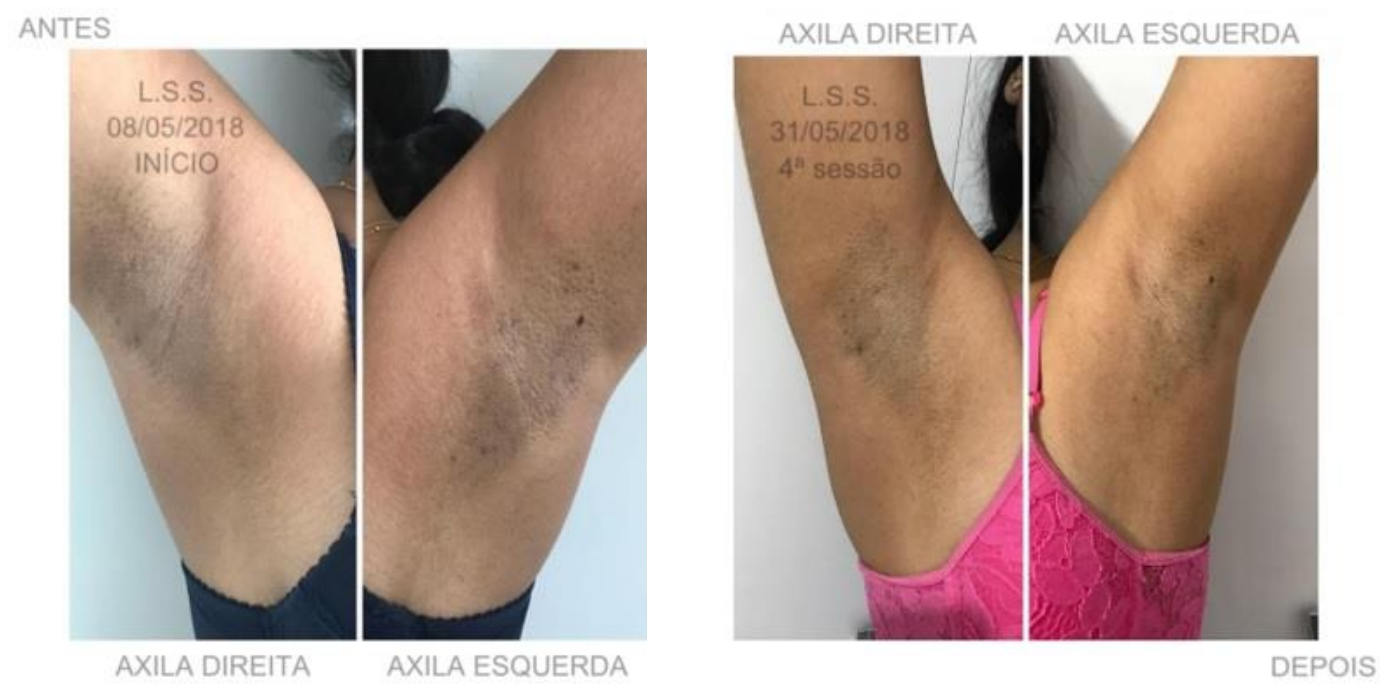


\section{Voluntária L.S.S.}

- 23 anos, sexo feminino, parda, fototipo III de acordo a classificação de Fitzpatrick. Considera sua axila pigmentada, relatando ocorrência desde a adolescência, após a terceira sessão apresentou resultado na eficácia da formulação.
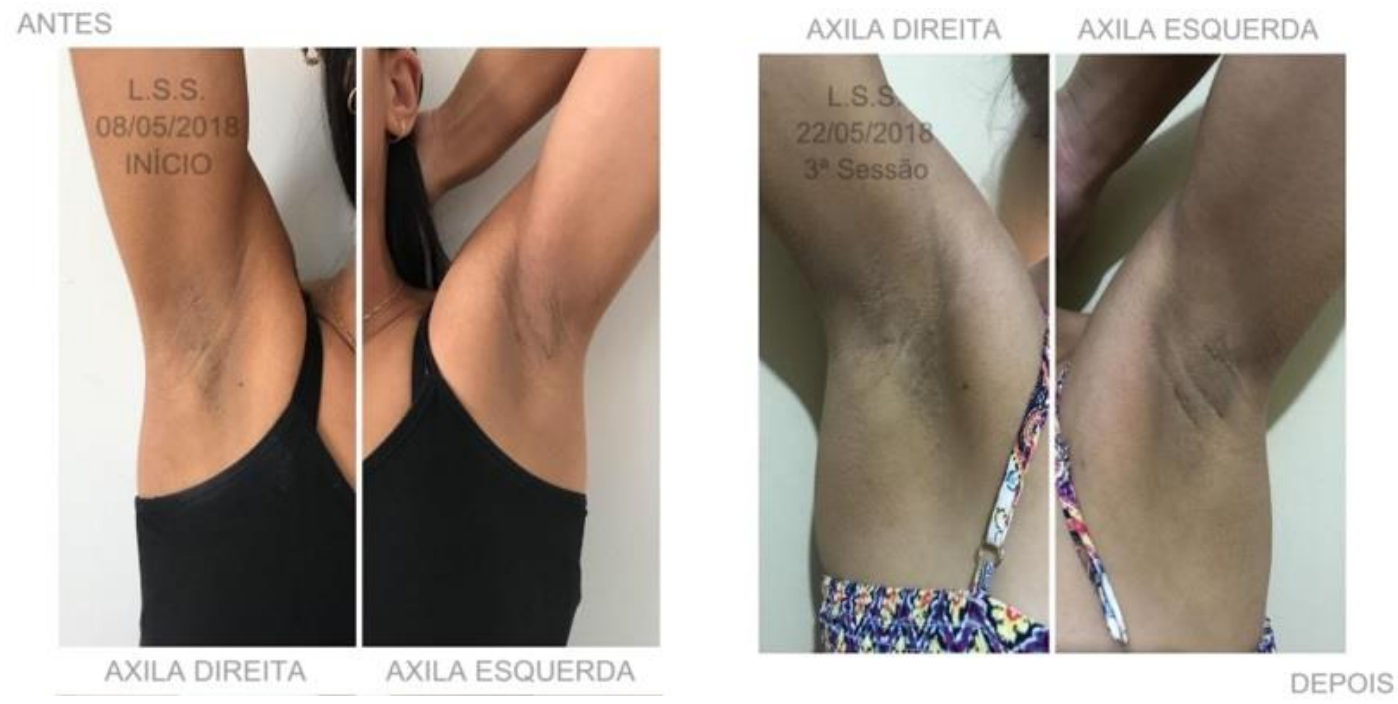

\section{Voluntária M.S.R.}

- 24 anos, sexo feminino, negra, fototipo Iv de acordo a classificação de Fitzpatrick.

Considera sua axila pigmentada desde a adolescência, após a quarta sessão apresentou resultado satisfatório na eficácia da formulação, também relatou sensibilidade a gaze utilizada no procedimento.

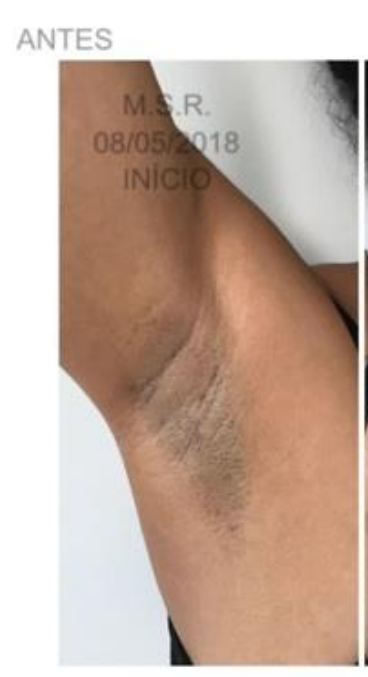

AXILA DIREITA

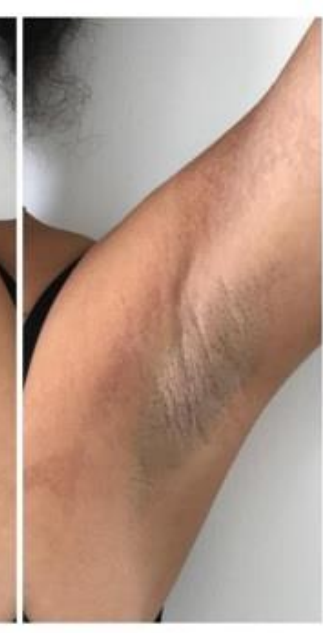

AXILA ESQUERDA

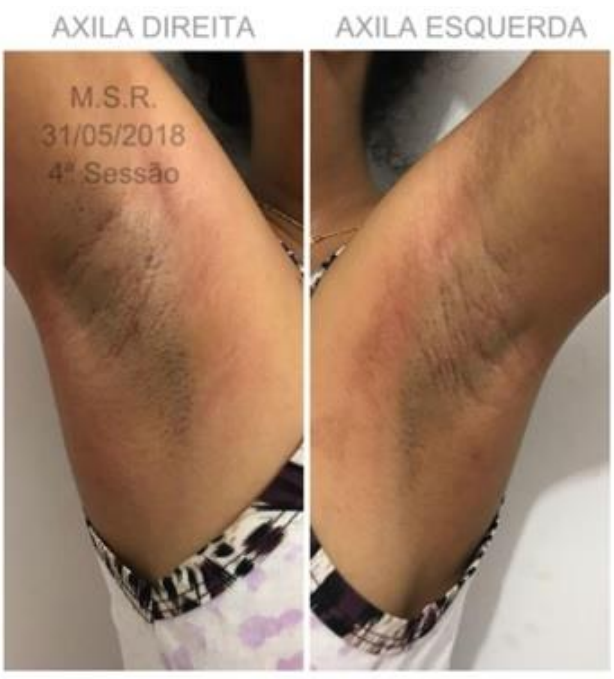

DEPOIS 


\section{Voluntária P.A.C.C.}

- 27 anos, sexo feminino, branca, fototipo II de acordo a classificação de Fitzpatrick. Considera sua axila pigmentada, relatando ter percebido após a gestação, ao realizar a quarta sessão apresentou resultado na eficácia da formulação.

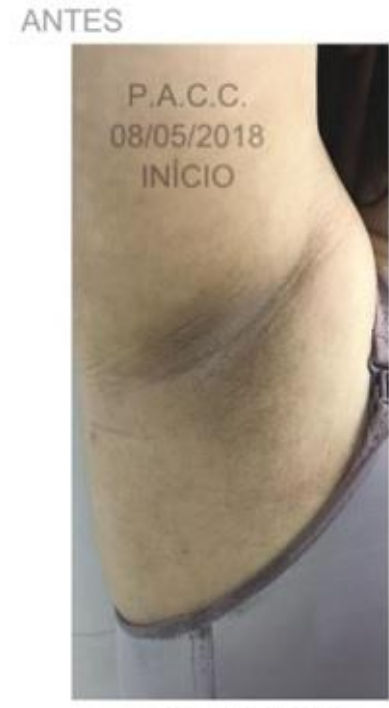

AXILA DIREITA

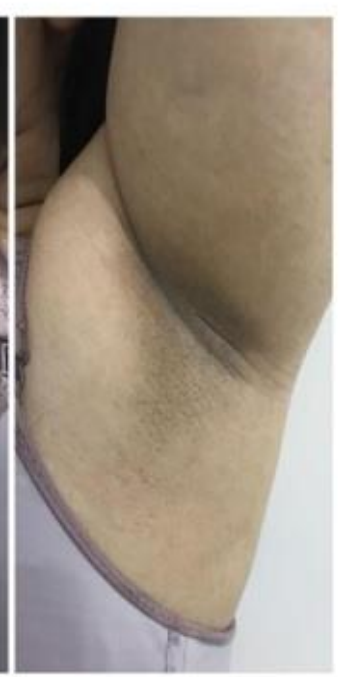

AXILA ESQUERDA

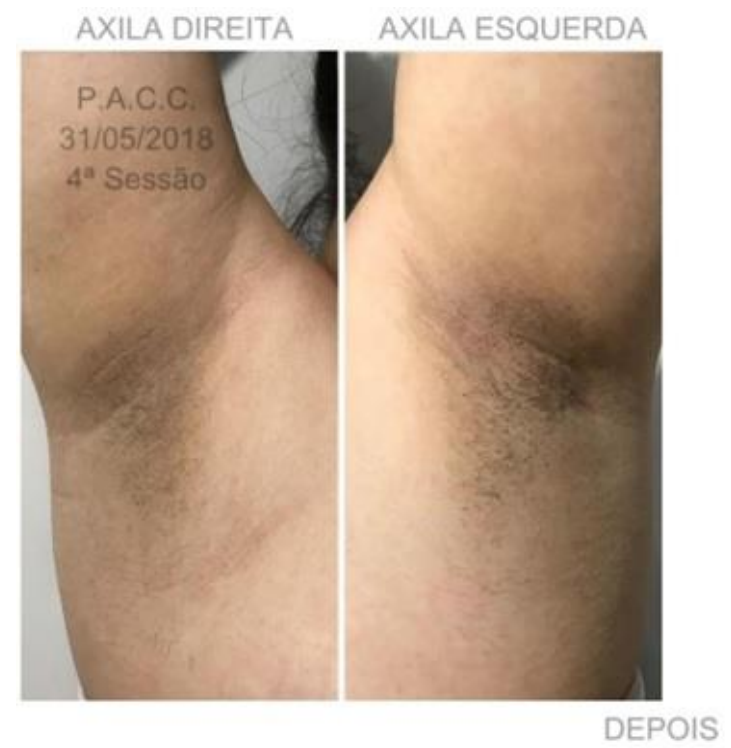

\section{Voluntária S.A.C.}

- 52 anos, sexo feminino, morena, fototipo II de acordo a classificação de Fitzpatrick.

Considera sua axila pigmentada, relatando ter percebido após a gestação, ao realizar a terceira sessão apresentou resultado na eficácia da formulação.
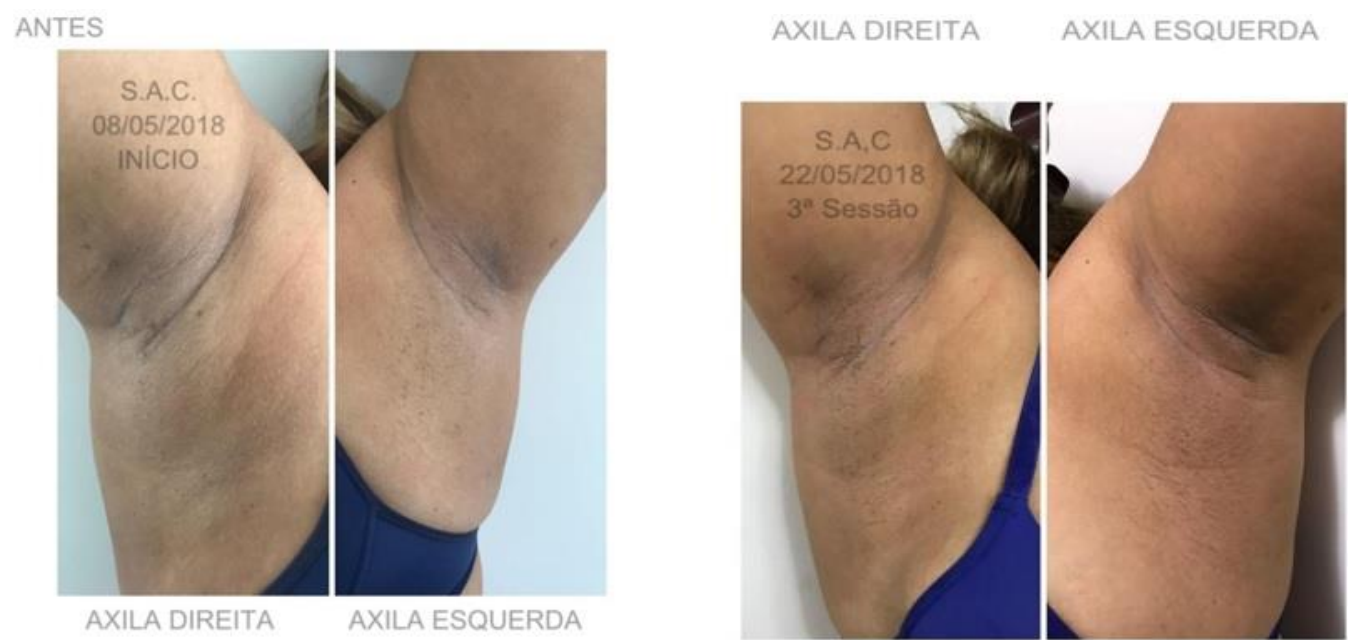


\section{Conclusões}

Na população utilizada foi percebido que em $100 \%$ houve relato de melhora na hiperpigmentação pós-inflamatória axilar. No entanto, não existe na literatura comprovação de que o composto penetre nas camadas mais profundas da epiderme, agindo nos melanócitos ou na melanogênese. Assim o presente estudo comprova a eficácia do clareamento superficial da pele através da ação antioxidante, bactericida, fungicida, anti-inflamatória, absorvente e clareadora dos componentes usados, eliminando as sujidades do extrato córneo causadas por bactérias e resíduos de cosméticos na região axilar.

\section{Referências}

ALCHORNE, M. M. A.; ABREU, M. A. M. Dermatologia na pele negra. Anais Brasileiros de Dermatologia, São Paulo, n.1 p. 7-20, jan. 2008.

AZULAY, R.D.; AZULAY, L.A. Dermatologia; 5a edição; Editora Guanabara Koogon; pp 104-112; 2011.

BORGES, F.S. Dermato-funcional Modalidades terapêuticas nas disfunções estéticas. $2^{\circ}$ edição; Editora Phorte, 327-351; 2010.

DIAS et al. Avaliação de parâmetros físico-químicos de mel de abelhas sem ferrão, vol. $2,2015$.

FRANK A.; ALEXANDER JR.; SEBASTIAN EGGERT; JOACHIM WIEST. Skin-on-aChip: Transepithelial Electrical Resistance and Extracellular Acidification Measurements through an Automated Air-Liquid Interface. Genes, London, 2018.

GIL, A.C. Como elaborar projetos de pesquisa. 5. ed. SP: Atlas, 2010.

GIL, A.C. Métodos e técnicas de pesquisa social. 5. ed. São Paulo: Atlas, 1999.

GONCHOROSKI, D.D.; CORRÊA, G. M. Tratamento da hipercromia pós- inflamatória com diferentes formulações clareadoras. Infarma, v. 17, n. 3/4, Ijuí. 2005.

HENDEL, A.C. et al. Melasma: uma avaliação cliníca e epidermológica. Anais Brasileiros de Dermatologia; RJ; vol 89; num 5; sept/oct, 2014. 
JAMES, A. G. et al. Histological evaluation of hyperpigmentation on female Filipino axillary skin. International Journal of Cosmetic Science, Florence, n.3, p.247-253, mar. 2006.

MIOT, L. D. B. et al. Fisiopatologia do melasma. Anais Brasileiros de Dermatologia, v. 84, n. 6, p. 62-35, 2009.

NICOLETTI, M.A. et al. Hipercromias: Aspectos Gerais e Uso de Despigmentantes Cutâneos, Cosmetics \& Toiletries, São Paulo, vol. 14, p. 46-51, mai-jun 2002.

OLIVEIRA, M. S. et al. Determinação da atividade antioxidante em amostras de própolis e geoprópolis de abelhas sem ferrão da Amazônia oriental, Belém - PA, 2015. Disponível em: https://www.embrapa.br/. Acesso em 20/11/2017.

PAIVA, K. B. S.; MENEZES, M. L. de. Avaliação do emprego dos adsorventes: carvão ativo, chromosorb W e membrana C18 na preparação de amostras de ar para a determinação de daletrina em ambientes fechados. Eclet. Quím., São Paulo, v. 28, n. 1, p. 97-103, 2003.

PEREIRA, D.S. et al. Classificação quanto a cor e composição de micronutrientes da própolis do leste potiguar, Belém - PA, 2015. Disponível em: https://www.embrapa.br/busca-de-publicacoes/-/publicacao/1020018/classificacao- quantoa-cor-e-composicao-de-micronutrientes-da-propolis-do-leste-potiguar.

Acesso em 20/11/2017.

RIBEIRO, C. Cosmetologia aplicada a dermatologia. 2. ed. São Paulo: Phamabooks, 2010.

SOUZA, V M.; JUNIOR, D. A. Ativos dermatológicos. In:

manchas e seus tratamentos. São Paulo: Pharmabooks, 2013. p. 250. v. 1 a 8. Tipos de

VENTURINI, K. S. SARCINELli, M. F. SilVA, L. C. Características do mel; Universidade Federal do Espírito Santo, 2007. Disponível em: http://agais.com/telomc/b01107 caracteristicas mel.pdf Acesso em: 20 de novembro de 2017.

\section{Como citar este artigo (Formato ABNT):}

COSTA, Patricia Angelica C.; ESPINHEIRA, Marcelo José Costa L. Clareamento de Hiperpigmentação pós-Inflamatória axilar por intermédio do Carvão Ativado associado ao Mel e a Própolis. Id on Line Revista Multidisciplinar e de Psicologia, 2018, vol.12, n.41, p.139-153. ISSN: 1981-1179.

Recebido: 14.05 .2018

Aceito: 18.05.2018 